\title{
Tenaga Kerja Sektor Formal Dan Informal Di Kabupaten Bangkalan
}

\author{
Yustina Chrismardani $^{1^{*}}$, Bondan Satriawan ${ }^{2}$ \\ ${ }^{1,2}$ Fakultas Ekonomi dan Bisnis Universitas Trunojoyo Madura
}

\section{Informasi Artikel \\ Sejarah artikel: \\ Diterima Februari 2018 \\ Disetujui Februari 2018 \\ Dipublikasikan Maret \\ 2018}

\section{Keywords:}

Formal and Informal Sector,

Labor Mobility

\begin{abstract}
A BS TRACT
One of the interesting things studied from Kabupaten Bangkalan is the aspect of employment, especially based on formal and informal sector. Based on the formal sector workers who belong to the category of workers / workers and tried to be assisted by permanent workers / workers paid up to 76 percent, and informal workers are who try their own, trying to be assisted by temporary workers, free workers in agriculture, free workers in non-paid to reach 24 percent. Other important findings indicate that there is no significant difference in the total income of workers in the formal and formal sectors, which is an average of Rp 76,184, and it turns out that Bangkalan regency has not been the target of workers migration from the surrounding area.
\end{abstract}




\section{Pendahuluan}

Salah satu hal yang menarik dikaji dari Kabupaten Bangkalan adalah dari aspek ketenagakerjaan, khususnya berdasar kriteria formal dan informal. Berdasarkan kriteria pekerja-pekerja yang termasuk kategori buruh/karyawan dan berusaha dibantu buruh tetap/buruh dibayar dan pekerja informal adalah pekerja yang berusaha sendiri, berusaha dibantu buruh tidak tetap, pekerja bebas di pertanian, pekerja bebas di non pertanian dan pekerja tak dibayar maka tampak kondisi ketenagakerjaan di Bangkalan dan Sampang. Tampak pada Gambar 1 jumlah pekerja di Bangkalan masih didominasi oleh jenis pekerja sektoral, padahal di pekerja jenis informal biasanya mendapatkan perlindungan yang kecil dengan jenis pekerjaan yang kurang bagus (ILO 2014).

Eksistensi tenaga kerja dapat dilihat dari beberapa perspektif, salah satunya adalah peranannya yang penting sebagai faktor produksi. Faktor produksi adalah input yang digunakan untuk menghasilkan barang dan jasa. Dua faktor produksi yang memiliki peranan penting adalah modal dan tenaga kerja. Modal adalah seperangkat sarana yang dipergunakan oleh tenaga kerja, misalnya derek pada pekerjaan bangunan, kalkulator akuntan dan lain sebagainya. Sedangkan tenaga kerja adalah waktu yang dihabiskan orang untuk bekerja (Mankiw 2007).
Berangkat dari kondisi tersebut maka perlu diidentifikasi dan ditemukenali kendala yang membatasi pekerja informal masuk ke pasar kerja formal, antara lain mencakup kondisi sosial ekonomi pekerja formal dan informal serta kendala pekerja informal bermigrasi ke sektor formal, serta rumusan strategi yang dilakukan oleh Pemda Bangkalan, khususnya Dinas Sosial, Tenaga Kerja dan Transmigrasi serta Dinas Koperasi UMKM.

Penelitian ini penting dilaksanakan karena akan menghasilkan profil tenaga kerja pekerja formal dan informal di Kabupaten Bangkalan, yang meliputi tempat tinggal, tingkat pendidikan, kondisi sosial ekonomi, pengalaman kerja. Analisis lain yang dapat diperoleh dari penelitian ini adalah migrasi pekerja di Kabupaten Bangkalan. Migrasi tenaga kerja secara umum didefinisikan sebagai gerakan lintas batas untuk tujuan kerja di negara asing. Namun, tidak ada definisi yang diterima secara universal migrasi tenaga kerja. Definisi lain menyatakan migrasi adalah perpindahan penduduk dari suatu wilayah lain dengan maksud untuk menetap didaerah tujuan. Berdasarkan pengelompokannya, mobilitas penduduk dapat dibagi menjadi 2 bentuk yaitu mobilitas permanen atau migrasi dan mobilitas non permanen atau mobilitas sirkuler. Sedangkan mobilitas non permanen ialah gerakan penduduk dari suatu tempat ke tempat lain dengan

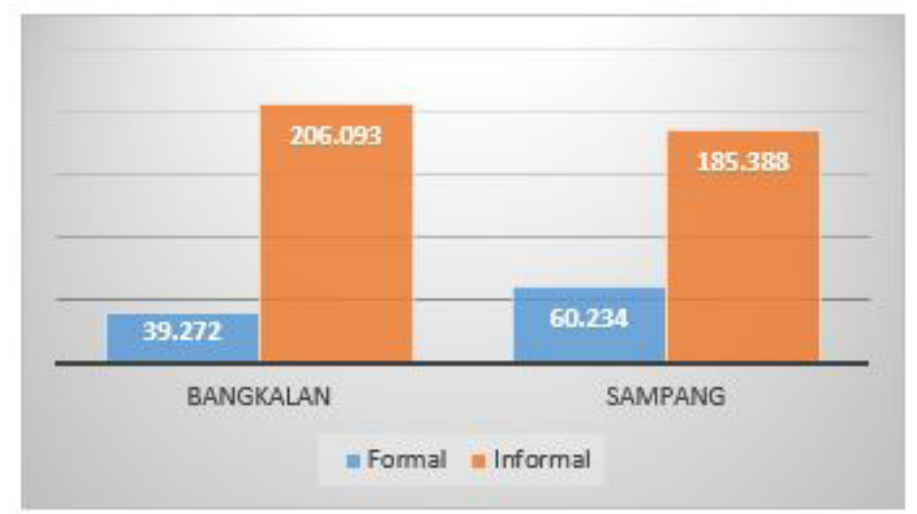

Sumber: Keadaan Tenaga Kerja Jawa Timur tahun 2015

Gambar 1. Kondisi Ketengakerjaan Bangkalan Dan Sampang 2015 
tidak ada niatan untuk menetap didaerah tujuan, dan mobilitas permanen ialah perpindahan penduduk dari suatu daerah ke daerah lain dengan maksud untuk menetap di daerah tujuan (Mantra 2012).

Rumusan masalah yang muncul dari masalah diatas adalah bagaimanakah profil tenaga kerja sektor formal dan informal di Kabupaten Bangkalan, dan bagaimanakah pola migrasi tenaga kerja di Bangkalan?

\section{Tinjauan Pustaka}

Pasar Kerja Sektor Formal dan Informal

Sektor formal dan informal memiliki definisi yang berbeda dari berbagai sudut pandangnya. Masing-masing peneliti dan referensi memiliki dasar dan teknis analisis yang berbeda pula dan membedah kedua sektor tersebut. (Perkins et al. 2012) membagi pasar tenaga kerja menjadi tiga bagian, yaitu sektor formal perkotaan (urban formal sector), sektor informal perkotaan (urban informal sector) dan pasar kerja pedesaan (rural employment). Sektor formal perkotaan (urban formal sector) merupakan pasar kerja yang diinginkan oleh setiap pekerja, baik pria maupun wanita. Pada pasar ini terdapat sektor pemerintah dan perusahaan besar seperti bank, perusahaan asuransi, pabrik dan perdagangan. Masyarakat dapat bekerja pada sektor ini dengan fasilitas yang lebih modern daripada jenis pasar kerja yang lainnya, dan merupakan daya tarik tersendiri adalah tingkat upah yang paling tinggi dan menawarkan pekerjaan yang menarik. Salah satu alasan mengapa tingkat upahnya lebih tinggi karena yang bekerja pada pasar tersebut kebanyakan memiliki tingkat pendidikan tinggi dan menengah dari berbagai penjuru daerah.

Yang menarik adalah mengapa pakerja pada pasar ini harus dibayar lebih? (Perkins et al. 2012) menjelaskan bahwa salah satu latar belakangnya adalah ketentuan pemerintah melalui kebijakan upah minimum, meskipun pada aplikasinya ti- dak jarang pengusaha menerapkan kebijakan tersebut dengan sukarela karena berdasarkan pendekatan Efficiency Wage yang menyebutkan bahwa produktivitas pekerja memiliki fungsi positif dengan upah yang dibayarkan kepada mereka, karena (1) pekerja akan mendapatkan gizi yang lebih baik sehingga memiliki kemampuan kerja yang lebih baik pula dan (2) dengan upah yang tinggi maka pengusaha dapat menyeleksi pekerjanya dengan lebih selektif. Bagi pekerja sendiri, upah yang tinggi dapat menyebabkan mereka bertahan lebih lama pada suatu pekerjaan, learning by doing dan mengurangi tingkat mutasi pekerja (labor turn over).

Jenis pasar kerja berikutnya adalah sektor informal perkotaan (urban informal sector) yang di dalamnya terdapat perusahaan yang lebih kecil. Terkadang tepi jalan merupakan tempat menjual/toko dan tempat produksi berbagai jenis barang dan jasa mereka. Kadangkala mereka harus berkompetisi dengan perusahaan yang lebih besar, dan terkadang mereka harus eksis pada permintaan yang tidak menguntungkan bagi sektor formal.

Tidak jarang pula sektor informal kota ini memberikan lapangan pekerjaan bagi pekerja migran yang berasal dari pedesaan untuk mencari kerja di kota. Studi pada beberapa negara dunia ketiga ternyata mengindikasikan bahwa pekerja pada sektor ini merupakan orang yang telah lama tinggal di kota dan veteran. Salah satu ciri khas dari sektor ini adalah mudah dimasuki oleh pekerja, meskipun ada kalanya kehadirannya justru dapat menurunkan tingkat upah bagi seluruh pekerja.

Meskipun sektor informal kota sering memberikan tingkat upah yang lebih tinggi daripada pasar tenaga kerja di pedesaan (rural labor market), hanya saja sebenarnya hal ini terkesan dibuatbuat karena untuk tinggal dan hidup dikota harus membayar biaya hidup yang lebih tinggi, baik untuk makanan dan tem- 
pat tinggal, dan sering kali mereka harus mengeluarkan biaya yang seharusnya tidak perlu dikeluarkan bilamana mereka tetap tinggal di desa.

Berbeda dengan Perkin, (Gindling \& Terrel 2004) dalam penelitiannya mendefinisikan pekerja sektor formal perkotaan merupakan seluruh pekerja pada perusahaan besar di kota beserta seluruh pekerja berpendidikan universitas atau bagi pekerja yang diklasifikasikan sebagai profesional atau teknisi (tidak membedakan dimana mereka bekerja), sedangkan seluruh pekerja di daerah pedesaan diklasifikasikan sebagai pekerja sektor informal. Sedangkan Bird dan Manning (2002) mendefinisikan pekerja sektor informal sebagai pekerja tanpa upah, yaitu pekerja yang bekerja mandiri dan pekerja keluarga yang tidak dibayar, demikian juga para pekerja yang menerima bayaran di usaha kecil.

\section{Metode Peneltian \\ Ruang Lingkup Penelitian}

Lingkup penelitian ini meliputi keseluruhan proses dan kegiatan untuk mengetahui pola permintaan tenaga kerja di Kabupaten Bangkalan sebagai acuan dalam menentukan kebijakan dalam bidang ketenagakerjaan, yang antara lain meliputi: a) Pengumpulan data primer melalui survey kepada tenaga kerja sektor formal dan informal di Kabupaten Bangkalan dengan instrumen kuesioner. Responden tersebar pada beberapa kecamatan, antara lain Kecamatan Bangkalan, Kecamatan Kamal, Kecamatan Socah, Kecamatan Labang, Kecamatan Burneh, Kecamatan Kwanyar dan Kecamatan Tanjung Bumi. b) Melakukan pengumpulan data yang berasal dari hasil survey Tenaga Kerja Nasional (SAKERNAS) yang diterbitkan oleh Biro Pusat Statistik (BPS) dan data Bangkalan dalam Angka. c) Melakukan pengumpulan data tambahan dari dinas dan instansi terkait, seperti Dinas Sosial, Tenaga Kerja dan Transmigrasi.

\section{Teknik Analisis}

Analisis sekunder adalah teknik analisis penelitian sosial dengan cara menggunakan data-data yang tersedia sebelum penelitian (dokumentasi). Analisis sekunder digunakan untuk menggambarkan berbagai praktik analisis yang menggunakan pra-data yang ada, baik untuk menyelidiki pertanyaan-pertanyaan penelitian baru atau untuk memeriksa kembali pertanyaan-pertanyaan penelitian utama untuk tujuan menguatkan. Analisis sekunder biasanya sangat cocok untuk data statistik yang telah lengkap dan terdokumentasi dengan baik. Sedangkan untuk analisis data primer mengunakan metode survey. Tujuan penelitian survey adalah untuk meneliti tentang karakteristik dari seluruh kelompok yang hendak diteliti atau populasi dengan meneliti sebagian (subset) dari kelompok populasi tersebut yang selanjutnya disebut dengan sampel. Hasil dari survey terhadap sampel tersebut kemudian digeneralisasikan atau diberlakukan kepada populasi. Penelitian survey biasanya didefinisikan sebagai sebuah penelitian atau penelitian tentang kelompok besar melalui penelitian langsung dari subset (sampel) dari kelompok tersebut.

Teknik yang digunakan adalah diantaranya: (1) wawancara terstruktur (structured interview); (2) statistik survei dan kuesioner (statistical surveys and questionnaires) kelompok responden atau fokus studi yang akan bermanfaat untuk membandingkan/kontras tanggapan peserta untuk menjawab pertanyaan penelitian.

Klasifikasi pekerja sektoral berdasarkan kategori buruh/karyawan dan berusaha dibantu buruh tetap/buruh dibayar. Sedangkan untuk pekerja yang bekerja pada sektor informal, yaitu sektor selain sektor formal, meliputi berusaha sendiri, berusaha dibantu buruh tidak tetap, pekerja bebas di pertanian, pekerja bebas di non pertanian dan pekerja tak dibayar. 
Dasar yang digunakan untuk membedakan sektor formal dan informal adalah berdasarkan Status Pekerjaan Utama oleh BPS (2011), karena sumber data yang digunakan adalah Survei Angkatan Kerja Nasional yang dilaksanakan oleh BPS.

\section{Obyek penelitian}

Pada survey ini, responden adalah tenaga kerja sektor formal dan informal, sejumlah 150 responden (Tabel 1). Beberapa aspek yang menjadi fokus pada penelitian ini adalah status sosial ekonomi responden dan pola migrasi, baik migrasi sektoral maupun migrasi antar wilayah, dan lain sebagainya.

sektoral tenaga kerja yang berasal dari Survei Tenaga Kerja Nasional (SAKERNAS), Survei Sosial Ekonomi Nasional (SUSENAS). Data upah minimum kabupaten/kota di Propinsi Jawa Timur dan data nilai tambah sektor industri yang dikumpulkan oleh BPS.

Kedua, Data Primer. Data primer merupakan data yang diperoleh dengan survei lapangan yang menggunakan semua metode pengumpulan data original (Kuncoro 2001). Data primer yang digunakan dalam penelitian ini adalah wawancara (in-depth interview) dengan pihak yang terkait dengan proses pengambilan kebijakan di bidang ketenagakerjaan di tingkat Propinsi Jawa Timur.

Tabel 1.

\begin{tabular}{clc}
\multicolumn{3}{c}{ Nilai Skor Karakter Fisik Daerah Aliran Sungai } \\
\hline NO & KECAMATAN & JUMLAH RESPONDEN \\
\hline 1 & Bangkalan & 37 \\
\hline 2 & Kamal & 29 \\
\hline 3 & Socah & 28 \\
\hline 4 & Labang & 17 \\
\hline 5 & Burneh & 17 \\
\hline 6 & Kwanyar & 12 \\
\hline 7 & Tanjungbumi & 10 \\
\hline & Jumlah & 150
\end{tabular}

Kerangka sampel yang digunakan dalam survey ini adalah Stratified Cluster Random Sampling. Pada metode ini seluruh populasi dibagi menjadi beberapa cluster (kelompok) yang memiliki karakter sama atau hampir sama, dan menentukan cluster berdasarkan strata atau tingkatan sesuai dengan kriteria penelitian. Langkah selanjutnya adalah memilih secara random (acak) unit-unit individu penelitian di masing-masing cluster dan stratayang akan digunakan sebagai sampel responden.

\section{Jenis dan sumber data}

Jenis data yang digunakan dalam penelitian ini terdiri dari data sekunder dan data primer, berikut penjelasaannya: Pertama, Data Sekunder. Data ini adalah data yang dikumpulkan oleh pihak lain, antara lain data ketenagakerjaan sektor formal dan informal serta kategori lapangan kerja

\section{Hasil Penelitian}

Profil Tenaga Kerja Sektor Formal dan Informal

Penelitian dilakukan dengan melakukan survey di 7 kecamatan dengan jumlah responden sejumlah 150 orang. Berdasarkan klasifikasi pekerja sektor formal berdasarkan kategori buruh/karyawan dan berusaha dibantu buruh tetap/buruh dibayar. Sedangkan untuk pekerja yang bekerja pada sektor informal, yaitu sektor selain sektor formal, meliputi berusaha sendiri, berusaha dibantu buruh tidak tetap, pekerja bebas di pertanian, pekerja bebas di non pertanian dan pekerja tak dibayar. Ternyata klasifikasi pekerja sektor formal masih mendominasi di Kabupaten Bangkalan sebesar 76 persen, sedangkan sisanya sebesar 24 persen pekerja informal (Gambar 2). 


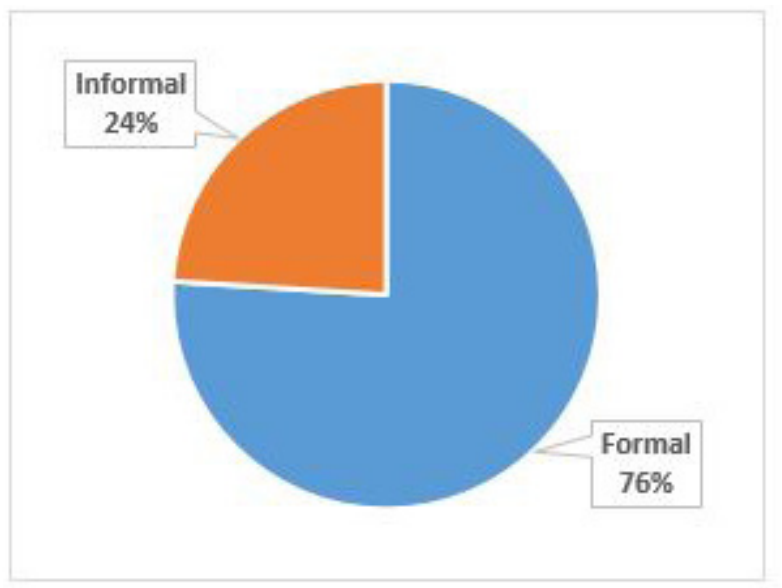

Sumber : Hasil Survey

Gambar 2.

Pekerjaan Utama Responden

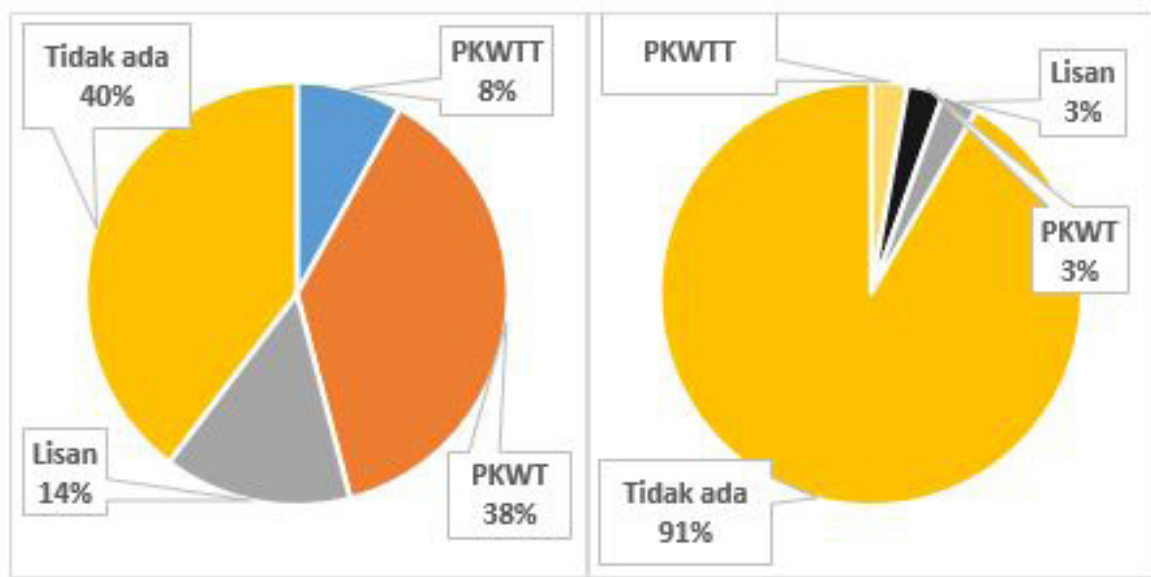

A. Pekerja Sektor Formal

B. Pekerja Sektor Informal

Sumber: Hasil Survey

Gambar 3.

Perjanjian Kerja

Hanya saja yang disayangkan adalah hanya sedikit pekerja di sektor formal hanya terikat pada Perjanjian Kerja Waktu Tidak Tentu (PKWTT) sebesar 8 persen. PKWTT adalah perjanjian kerja antara pekerja/buruh dengan pengusaha untuk mengadakan hubungan kerja yang bersifat tetap. PKWTT dapat dibuat secara tertulis maupun secara lisan dan tidak wajib mendapatkan pengesahan dari instansi ketenagakerjaan terkait. Jika PKWTT dibuat secara lisan, maka klausulklausul yang berlaku di antara mereka (antara pengusaha dengan pekerja) adalah klausul-klausul sebagaimana yang di atur dalam UU Ketenagakerjaan. PKWTT dapat mensyaratkan masa percobaan kerja paling lama 3 (tiga) bulan. Selama masa percobaan pengusaha wajib membayar upah pekerja dan upah tersebut tidak boleh lebih rendah dari upah minimum yang berlaku.

Sementara 38 persen pekerja formal terikat pada kontrak Perjanjian Kerja Waktu Tertentu (PKWT), yaitu perjanjian kerja antara pekerja/buruh dengan 
pengusaha untuk mengadakan hubungan kerja dalam waktu tertentu atau untuk pekerjaan tertentu yang bersifat sementara (Pasal 1 angka 1 Keputusan Menteri Tenaga Kerja dan Transmigrasi Nomor KEP 100/ MEN/VI/2004 tentang Ketentuan Pelaksanaan Perjanjian Kerja Waktu Tertentu, selanjutnya disebut Kepmen 100/2004.

Kondisi yang perlu mendapatkan perhatian adalah proporsi pekerja tanpa ikatan kerja, baik pada sektor formal dan informal. Hal ini perlu mendapatkan perhatian dari pihak terkait, khususnya kesadaran dari pihak perusahaan dan pemerintah.
Usaha yang diharapkan dapat meningkatkan jenis pekerjaan di sektor formal antara lain adanya kemudahan dari Pemerintah Daerah Kabupaten Bangkalan agar memudahkan proses pengajuan perizinan usaha. Sektor perbankan juga harus meningkatkan penyaluran kredit produktif dengan skema kredit murah, yaitu tingkat bunga yang rendah dengan waktu pengembalian yang panjang. Demikian juga Dinas Tenaga Kerja, yaitu dengan mengadakan pelatihan-pelatihan bagi calon pekerja sehingga dapat menyiapkan tenaga kerja terampil.

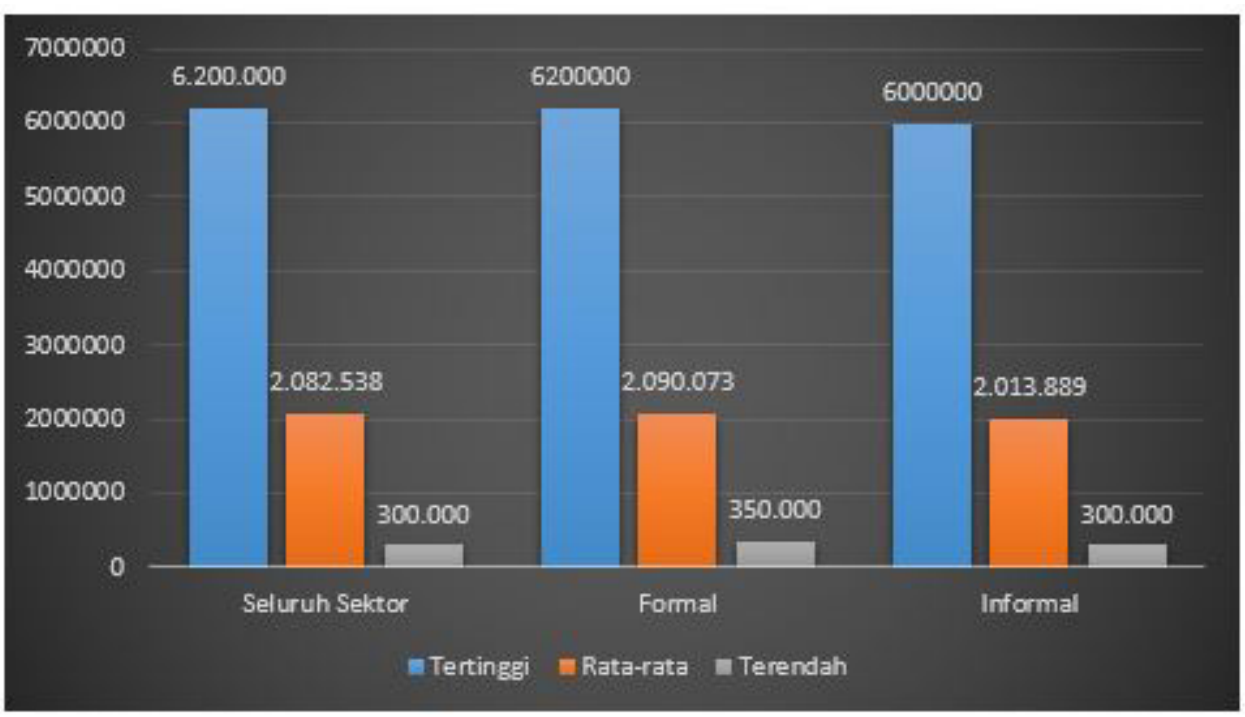

Gambar 4.

Tingkat Pendapatan

Tingkat pendapatan di Kabupaten Bangkalan ternyata tidak telalu berbeda antara sektor formal dan informal (Gambar 4). Selisih penghasilan tertinggi hanya sebesar Rp 200.000 dan hanya Rp 76.184 pada tingkat rata-rata pendapatan. Hal ini menunjukkan bahwa masih dimungkinkannya perkembangan jenis pekerjaan di Kabupaten Bangkalan, khususnya pada sektor formal agar dapat bertambahnya jenis pekerjaan yang dapat menawarkan tingkat penghasilan yang lebih tinggi.

\section{Migrasi Pekerja}

Migrasi adalah perpindahan penduduk dari satu wilayah menuju wilayah lainnya, yang dalam penelitian ini digunakan batasan "pekerja migran" adalah pekerja yang berdomilisi di Kabupaten Bangkalan kurang dari 7 bulan sebelum dilakukan survey. Dan berdasar hasil survey ternyata hanya 2 persen pekerja yang merupakan pekerja migran (Gambar 5), dan responden tersebut ternyata melakukan perpindahan karena mencari penghasilan yang lebih baik. Hal tersebut menujukan bahwa jenis 
pekerjaan di Kabupaten Bangkalan belum banyak menarik pekerja dari wilayah lain untuk berpindah domisili dan bekerja di Kabupaten Bangkalan. Hal tersebut juga terkait dengan belum terlalu beragamnya jenis pekerjaan di wilayah tersebut. lan yang semakin tinggi.

Kedua, pihak-pihak yang diharapkan dapat meningkatkan jenis pekerjaan di Kabupaten Bangkalan antara lain: a) Adanya kemudahan dari Pemerintah Daerah Kabupaten Bangkalan agar memudahkan proses pengajuan perizinan usaha dan

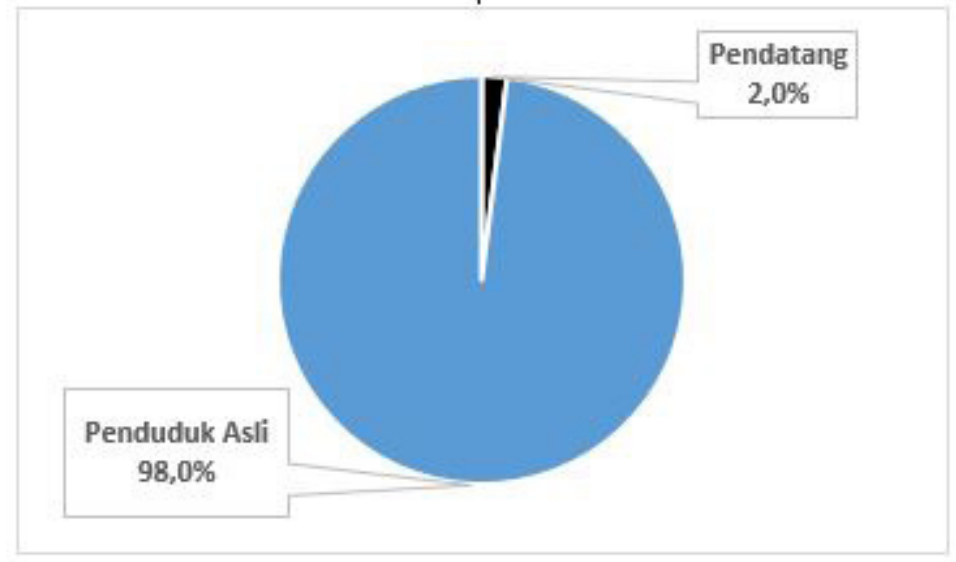

Gambar 5.

Asal Responden

\section{Kesimpulan dan Saran Kesimpulan}

Kesimpulan yang dapat diambil dari penelitian ini adalah : a) Jumlah pekerja di sektor formal sebesar 76 persen, yaitu kategori-kategori buruh/karyawan dan berusaha dibantu buruh tetap/buruh dibayar. b) Jumlah pekerja di sektor informal sebesar 24 persen, yaitu meliputi berusaha sendiri, berusaha dibantu buruh tidak tetap, pekerja bebas di pertanian, pekerja bebas di non pertanian dan pekerja tak dibayar. c) Belum terdapat perbedaan signifikan atas jumlah pendapatan pekerja di sektor formal dan informal yaitu ratarata sebesar Rp 76.184. d) Kabupaten Bangkalan belum banyak menjadi tujuan migrasi pekerja dari wilayah sekitarnya

\section{Saran}

\section{Pasar Tenaga Kerja}

Pertama, perlunya pengembangan potensi jenis pekerjaan di Kabupaten Bangkalan khususnya pada sektor formal agar dapat bertambah jenis pekerjaan yang dapat menawarkan tingkat penghasi- pengaturan sentra ekonomi di pusat kabupaten. b) Sektor perbankan meningkatkan penyaluran kredit produktif dengan skema kredit murah, yaitu tingkat bunga yang rendah dengan waktu pengembalian yang panjang. c) Dinas Sosial, Tenaga Kerja dan Transmigrasi serta Dinas Koperasi UMKM, yaitu dengan mengadakan pelatihan-pelatihan bagi calon pekerja sehingga dapat menyiapkan tenaga kerja terampil. d) Balai Latihan Kerja yaitu dengan: (i) Melakukan evaluasi efektifitas pelatihan yang ada, sehingga pelatihan yang diberikan benarbenar mampu memfasilitasi para peserta untuk menciptakan lapangan pekerjaan bagi dirinya sendiri. (ii) Peningkatan penjalinan kerjasama dengan lembaga penyedia sertifikasi kompetensi, terutama untuk penyediaan tes kompetensi secara gratis. (iii) Menjalin kerjasama dengan dinas lain atau organisasi kemasyarakatan atau menggandeng program CSR perusahaan untuk pengembangan sarana dan prasarana BLK. 


\section{Daftar Pustaka}

Borjas, G., 2013. Labor Economics 6th ed., New York: Mc Graw-Hill Irwin.

Gindling, T. \& Terrel, K., 2004. Legal Minimum Wages and the Wages of Formal and Informal Sector Workers in Costa Rica, Michigan. Available at: https://deepblue.lib.umich.edu/bitstream/handle/2027.42/40033/wp647. pdf? sequence $=3$.

ILO, 2014. Indonesia: Tren Sosial dan Ketenagakerjaan Agustus 2014, Jakarta. Available at: http://www.ilo.org/wcmsp5/ groups/public/---asia/---ro-bangkok/--ilo-jakarta/documents/publication/ wcms_329870.pdf.

Kuncoro, M., 2001. Metode Kuantitatif: Teori dan Aplikasi untuk Bisnis dan Ekonomi, Yogyakarta: UPP AMP YKPN.

Kusumosuwidho, S., 2001. Angkatan Kerja. In Dasar-Dasar Demografi. Jakarta: Lembaga Demografi. FE-UI.

Mankiw, N.G., 2007. Makroekonomi 6th ed. Wibi Hardani, Devri Barnadi, \& Suryadi Saat, eds., Jakarta: Erlangga.

Mantra, I.B., 2012. Demografi Umum, Jakarta: Pustaka Pelajar.

Perkins, D.H. et al., 2012. Economics of Development 7th ed., W.W. Norton \& Company, Inc.

Sumarsono, S., 2009. Teori dan Kebijakan Publik Ekonomi Sumber Daya Manusia, Jakarta: Graha IImu. 